\title{
JUVENTUDE E CRIMINALIDADE SOB A PERSPECTIVA DA ESCOLA DE CHICAGO
}

\section{YOUTH AND CRIME IN THE PERSPECTIVE OF CHICAGO SCHOOL}

Marconi do Ó Catão 1

\section{Mariana Cavalcanti Pereira ${ }^{2}$}

RESUMO: Este texto objetiva, a partir das crescentes referências bibliográficas relacionadas com a juventude e a criminalidade, realizar uma análise desta dupla relação, utilizando-se, para tanto, das contribuições advindas da Escola de Chicago, tendo a Ecologia Humana como uma de suas mais importantes teorias, onde irá estabelecer a cidade como seu principal laboratório, mais especificamente, nas comunidades localizadas em áreas urbanas consideradas degradadas, verificando os fatores potencializadores de diversos problemas sociais, sobretudo, da violência urbana. Nesse contexto, foi dada uma especial atenção aos fenômenos sociais abrangendo os jovens, buscando compreender os elementos que prevalecem nesta categoria e concorrem para o seu ingresso na criminalidade. Além do mais, no decorrer deste estudo, verificou-se a necessidade de uma mudança de paradigmas no tratamento dos jovens em conflito com a lei, pensando-se, principalmente, em uma nova política de prevenção, abandonando, assim, o modelo clássico de repressão. Quanto aos aspectos metodológicos, utilizamos o procedimento analítico-descritivo, tendo sido realizado um levantamento bibliográfico nas literaturas nacional e internacional que dizem respeito à matéria. A justificativa do desenvolvimento deste trabalho está no sentido de apresentar as principais referências conceituais e teóricas que compõem o estudo realizado pela Escola de Chicago como um parâmetro para consequentes reflexões sobre a necessidade de integração entre as diferentes áreas do saber, com posteriores aplicações no âmbito das cidades brasileiras, para que então seja possível conhecermos de fato os problemas que atingem nossa realidade, particularmente para o auxílio das Ciências Jurídicas, que jamais devem permanecer na inércia, necessitando sempre de constantes adaptações à sociedade contemporânea.

Palavras-chave: Escola de Chicago, Ecologia Humana, juventude, criminalidade.

ABSTRACT: This work aims, from increasing bibliographic references related to youth and criminality, to conduct an analysis of this double relation, using to this end, the contributions

\footnotetext{
${ }^{1}$ Doutor em Sociologia, pela Universidade Federal da Paraíba; Doutorando em Direito pela UERJ/UEPBDINTER; Mestre em Direito (Ordem Jurídica Constitucional) pela UFC; Especialista em Medicina Legal pela Associação Médica Brasileira e Sociedade Brasileira de Medicina Legal; Graduado em Medicina pela UFPB; Graduado em Direito pela UEPB; Coordenador Adjunto do Comitê de Ética em Pesquisa Científica em Seres Humanos da UEPB; Coordenador Setorial de Pesquisa do CCJ-UEPB; Membro da Associação Brasileira de Medicina Legal; Professor pesquisador da UEPB; Integrante da Sociedade Brasileira de Bioética. E-mail: moct@uol.com.br
}

${ }^{2}$ Mestranda do PPGCS/UFCG. Graduada em Direito pela UEPB. Membro dos Grupos de Pesquisa Sociabilidades e Conflitos Contemporâneos - SOCIATOS (CNPq/UFCG) e Direito, Tecnologia e Realidade Social: paradoxos, desafios e alternativas (CNPq/UEPB). E-mail: mari1917@gmail.com 
from the Chicago School and the Human Ecology as one of his most important theories which will establish the city as their main laboratory, more specifically in the communities localized in considered degraded urban areas, verifying the potential factors of various social problems, especially urban violence. In this context, there was a special focus on social phenomena involving young people, seeking to understand the elements that involves in this category and competes for his entry into crime. Furthermore, during this study, there was a need for a paradigm shift in the treatment of juveniles in conflict with the law, especially considering a new prevention policy, abandoning the classic model of repression. Regarding methodological aspects, we use the analytical-descriptive procedure in which we performed a bibliographic survey of the national and international literature pertaining to the matter. So that the justification of the development of this research is to put forward the main conceptual and theoretical references that make up the study conducted by the Chicago School as a parameter to subsequent reflections on the need for integration between different disciplines, with later applications in the context of Brazilian cities, so that it is possible to actually know the problems that plague our reality, primarily for the assistance of Legal Sciences that should never remain in inertia, always requiring constant adaptation to contemporary society.

Keywords: Chicago School, Human Ecology, youth, criminality.

\section{INTRODUÇÃO}

Com o crescente processo de industrialização, notadamente a partir do século XVIII, surgem inúmeros problemas sociais, frutos de um desenvolvimento econômico desigual. Assim, a segregação acompanha o alastramento das cidades, sobretudo das metrópoles, sendo que a divisão social do trabalho exerce papel crucial na construção da conjuntura urbana, intensificando, então, as questões localizadas. Logo, a pobreza passa a ser uma iniquidade frequentemente presente nos grandes centros, não mais estando relacionada apenas à vida rural.

Desse modo, foi sendo gradativamente estabelecido um viés entre as ideias de desigualdade social, pobreza e exclusão - tendo esta última uma relação de oposição com a coesão social, se aproximando das noções de estigma ou desvio - que muito auxilia no desenvolvimento das teorias do crime defendidas pela Escola de Chicago (NASCIMENTO, 2003, p.57). Portanto, foi na busca de identificar o desdobramento do processo responsável pelos problemas sociais que se deu uma atenção especial ao tema da violência urbana, principalmente no que concerne à esfera da criminalidade juvenil, área onde a instituição norte-americana em análise dedicou grande parte dos seus esforços.

Então, paulatinamente, a justificativa para as raízes da criminalidade pautada em elementos puramente psicogenéticos foi sendo deixada de lado, visto que desconsiderava outros aspectos como a cultura, por exemplo. Dessa maneira, os estudos começaram a se 
voltar para as explicações de cunho mais dinâmico, isto é, fatores psicológicos e biológicos, bem como os sociais objetivos, foram também considerados. Nesse contexto, autores como Park, Burgess, McKenzie, Mannheim, Parsons, Merton ${ }^{3}$, entre outros, deram relevantes contribuições, utilizando-se de conceitos como anomia, desvio social, desorganização social e geração, formando, assim, parte do escopo das teorias propostas pela Escola de Chicago a fim de elucidar a problemática da violência urbana.

Foi principalmente a partir do século XX que tal Escola investiu suas pesquisas nas questões da violência e criminalização, buscando compreender os fenômenos juvenis das gangues, analisando o aspecto do desvio social e de suas relações com os processos de adaptação à vida metropolitana. Nessa conjuntura social, portanto,surge a teoria da Ecologia Humana, fundada na perspectiva de analisar como a cidade - ou o habitat social - pode influenciar no comportamento dos indivíduos nela inseridos.

Com efeito, as teorias sociológicas apresentadas pela Escola de Chicago, especialmente a da Ecologia Humana, são atualmente compreendidas como referenciais de grande relevância para nortear muitos estudos na área da Criminologia, no sentido de traçar parâmetros mais dinâmicos no entendimento da relação entre o crime e os indivíduosem seus diferentes espaços e contextos sociais; e, também, no campo das Ciências Jurídicas, haja vista que se trata de uma área de conhecimento que, segundo Abramovay $(2002$, p. 15) alerta para a crise e, eventualmente, para a falência de marcos institucionais e normativos das sociedades modernas.

Assim, o objetivo central deste texto é, a partir dos pontos que foram brevemente destacados, demonstrar algumas contribuições da Escola de Chicago em relação ao estudo do crime, tendo como foco principal a delinquência juvenil. No desenvolvimento deste trabalho, apresentaremos dados relacionados com os indíces que se enquadram nessa faixa etária no âmbito de algumas cidades brasileiras.

\section{A ESCOLA DE CHICAGO: BREVE HISTÓRICO}

Em 1910, nos Estados Unidos, um grupo de sociólogos que compunham o Departamento de Sociologia da Universidade de Chicago formam a Escola Sociológica de

\footnotetext{
${ }^{3}$ MERTON, R. K. Sociologia: Teoria e estrutura. Tradução de Miguel Maillet. São Paulo. MestreJou, 1968; PARK, R. E; BURGESS, E. W. The City: suggestions for investigation of human behavior in the urban environment.London. The University of Chicago Press, 1967.
} 
Chicago, onde o principal cerne das discussões ali desenvolvidas se encontraria no estudo dos fenômenos urbanos, dando corpo, portanto, à chamada Sociologia Urbana. As pesquisas foram voltadas para tal área em decorrência do crescimento demográfico e do alargamento da extensão urbana que se processavam naquela cidade.

A Escola de Chicago tinha uma especial preocupação em realizar suas pesquisas por meio de abordagens formais e sistemáticas, tendo a coleta e análise de dados inspiração na experiência alemã, buscando, assim, produzir uma sociologia de caráter científico. De modo que o trabalho de campo, o estudo empírico e a observação direta dos fatos eram indispensáveis para a formulação de suas teorias. Ademais, os assuntos de maior interesse dessa Escola residiam em questões como urbanização, crime, juventude e família; para tanto, os sociólogos que ali realizavam seus trabalhos trouxeram contribuições de diversas áreas, a fim de promover uma integração entre os saberes, compondo uma sociologia que se encontrasse em um ambiente de interdisciplinaridade. Então, conceitos da Biologia, Psicologia, Filosofia e Geografia foram de enorme importância na construção dos estudos da cidade, esculpindo gradativamente as particularidades de tal Escola.

Para Downes e Rock apud Freitas (2002, p.54), os trabalhos desenvolvidos na França, em Manchester e na cidade de Londres eram consideráveis, tendo em vista que naquela época o Marxismo surgia na Europa. Contudo, foi em Chicago que houve a industrialização da Sociologia, tendo, assim, como uma de suas consequências, um estudo do crimeque, aos poucos, construía um sólido embasamento.

Portanto, foi por intermédio de três ramos da sociologia - formalismo, pragmatismo e reforma social -, que a Escola de Chicago traçou as linhas do pensamento dos seus estudos sociológicos: o formalismo se propôs a verificar as formas que dão base às relações em sociedade a fim de produzir uma espécie de equação da vida social; já o pragmatismonegava a busca de uma verdade imperiosa, mediante uma filosofia da ação ou da intervenção; e a reforma social, no âmbito dos estudos propostos pela referida Escola, procurava uma criação de vínculos entre os indivíduos desmotivados, assim como fontes para seu bem-estar (FREITAS, 2002, p. 55-56). Então, na articulação desses campos, a Sociologia Urbana, influenciada principalmente por Robert Park, vislumbra a cidade como um laboratório social, em especial nos grandes centros urbanos, onde a investigação do comportamento coletivo se realiza de maneira mais clara, estudando, para tanto, a sociedade dos pontos de vista biótico e sociológico; tendo este relação direta com os processos sociais ligados à vontade humana, 
enquanto que o primeiro diz respeito aos processos naturais autônomos da mencionada volição. Além disso, foi igualmente reconhecida a grande importância que tem a técnica da observação participante, aproximando-se, por conseguinte, do modelo etnográfico, trazendo, desse modo, mais consistência às atividades da Escola em análise.

Sem dúvida, um dos maiores trabalhos desenvolvidos pela referida Escola foi o Chicago Area Project, que inclusive tinha a pretensão situada justamente na questão da reforma social, voltada notadamente para o grupo social jovem. Liderado por Clifford Shaw, este projeto buscava a transformação concreta da realidade local de uma comunidade chamada Russel Square Park. De maneira que, inicialmente, as atividades recreativas foram oferecidas como cartão de convite, mas, a ideia de Shaw ultrapassava o mero caráter assistencialista. O maior desafio do Chicago Area Project era verificar os componentes daquela realidade, buscando promover o melhoramento da comunidade por meio de uma força que partisse dela mesma. Então, para isso, os moradores da própria Russel Square foram convidados para auxiliar nos trabalhos ali desenvolvidos, sendo esta atitude de enorme relevância para o sucesso do projeto, uma vez que os problemas seriam melhor identificados, compreendidos e tratados por aqueles de fato viviam tal dinâmica in concreto.

Em síntese, o projeto realizado na Russel Square concentrou seus esforços direcionados para o tema da delinquência, especificamente, a juvenil. Assim, fatores como exclusão, falta de supervisão familiar e comércio de procedência criminosa foram constatados naquela comunidade, sendo também observado que o grupo em questão era um dos principais envolvidos. Retomaremos essa discussão, de forma mais aprofundada, no tópico seguinte. Portanto, é por meio da teoria da Ecologia Humana que os sociólogos de Chicago traçam diversos estudos para a explicação da influência do ambiente social nos comportamentos desviantes.

De fato, o principal laboratório de estudos da Escola de Chicago era a cidade, mais especificamente os grandes centros urbanos, pois foram nestes locais que melhor foi observada a natureza do homem enquanto ser social, como bem destaca Park (1967:3), a cidade foi a mais próximo do seu desejo. Mas, se a cidade é o mundo que o homem criou, doravante ela é o mundo onde ele está condenado a viver. Assim, indiretamente, e sem qualquer percepção clara da natureza da sua tarefa, ao construir a cidade o homem reconstruiu a si mesmo. 
Além do mais, o conceito de ecologia foi adaptado para a sociologia, no sentido de se analisar a interação dos organismos - no caso, dos indivíduos. Consequentemente, termos como simbiose, invasão, dominação e sucessão são utilizados por Robert Park, Ernest Burgess e McKenzie na construção da concepção da Teoria da Ecologia Humana. Registre-se que a conjuntura em que surgiu tal teoria estava envolta de uma grande incidência de imigração nos Estados Unidos, havendo intensas discussões quanto as questões étnicas e de seus impactos nas cidades. Nesse contexto, assevera Coulon (1995, p.30) que:

[...] a este interesse da sociologia de Chicago pela questão da assimilação dos imigrantes que se deve a existência vários dos grandes conceitos da sociologia americana, entre os quais a desorganização social, a definição da situação, a marginalidade, a aculturação [...].

De maneira que, em consequência dessas transformações sociais, a cidade foi dividida em áreas, pois acreditava-se que havia forças dentro das comunidades, representadas por agrupamentos, de tal forma que era necessário o isolamento dos fatores, no intuito de se proceder a observação das tipicidades das pessoas e das instituições produzidas pelas operações conjuntas de tais forças. Assim, diferentemente da Escola Clássica, a Ecologia Humana defendia que a sociedade era quem impunha limitações ao livre arbítrio do homem, havendo, de certo modo, um pensamento revolucionário, pois até então o que se preconizava era a ideologia psicogenética.

Destarte, para a Ecologia Humana, as diferentes áreas encontravam-se em relação de simbiose, isto é, necessitavam uma da outra para existir, sendo elas provenientes de processos naturais e não da vontade humana, bem como participavam de uma relação de invasão e dominação, em diferentes aspectos e por diversos motivos. Em resumo, são esses elementos que vão atuar como as molas propulsoras das dúvidas suscitadas para os estudos da Escola de Chicago, sendo, para tanto, dedicadas várias pesquisas enfocando questões como pobreza, crise de valores, propriedade e delinquência.

Como podemos observar, para os estudiosos de Chicago, a cidade é um superorganismo, onde a perspectiva de vida coletiva é assumida como um processo concreto de relação entre meio-ambiente, população e organização; logo, o comportamento humano é fruto de vetores sócio-ambientais, e as mazelas presentes na sociedade advêm da desorganização social, não de um determinismo biológico. Então, é a partir desse pensamento 
que Burgess desenvolve um estudo sobre a cidade, no qual esta se expande em padrões de círculos concêntricos, criando, assim, a Teoria das Zonas Concêntricas, tendo como objetivo a comprovação da influência da estruturação urbana e social na vida dos indivíduos. Ademais, este sociólogo constatou na cidade de Chicago uma expansão radial, dividindo-a em cinco zonas, atribuindo, ao longo de suas pesquisas, particulares aspectos a cada uma delas; bem como verificando a atuação dos fatores de invasão, dominação e sucessão. Por fim, este autor conclui que muitos dos problemas sociais eram consequências de um processo de desorganização social, não sendo, portanto, a desorganização individual o padrão.

$\mathrm{Na}$ ótica da Escola de Chicago, a desorganização social é entendida como um dos fatores oriundos da rápida urbanização e do aumento da visibilidade das desigualdades sociais, ocasionando o enfraquecimento dos valores coletivos. De forma que, mudanças dos mais variados aspectos podem gerar tal fenômeno, incluindo transformações desde as de caráter tecnológico, natural, econômico, político etc. Em suma, todas as áreas da cidade são afetadas, de alguma maneira, pela desorganização social, só que em diferentes escalas os impactos são percebidos, visto que a desigualdade no acesso aos bens materiais e simbólicos é o que definirá quem são os excluídos, os marginalizados, os estigmatizados, entre outros grupos sociais igualmente presentes nas sociedades de um modo geral.

Nessa construção teórica, surge o entendimento de que as áreas degradadas são os espaços habitacionais deteriorados, sujeitos à violência e criminalidade, desprovidos, muitas vezes, de saneamento e de outros serviços básicos indispensáveis a um padrão de vida digna. Assim, essas áreas não chegam a ser consideradas nem mesmo como lugares de fato, haja vista que seus integrantes se encontram excluídos das métropoles, alheios aos recursos e espaços públicos.

Realmente, essas áreas deterioradas são constatadas, sobretudo, nas camadas pobres da sociedade, surgindo, então, um dos maiores problemas que enfrentamos hoje: o da estigmatização. A exclusão, segundo Nascimento (2003, p. 60) tem várias dimensões, sendo um processo de caráter múltiplo, ou seja: cultural, econômico e social. Porém, ressalte-se que, nessa discussão, a pobreza e a exclusão diferenciam-se do termo desigualdade social; até porque, a existência de um não necessariamente implica na do outro; assim, o que observamos é o recorrente campo comum que abriga estes três conceitos. Continuando, esclarece Nascimento (2003, p. 63) que: 


\begin{abstract}
A desigualdade social na sociedade moderna tem várias conotações. De forma simples, assinalo duas. Tem uma conotação positiva, na medida em que nela reside o processo de concorrência e desenvolvimento, onde se situam os eixos da inovação tecnológica e do dinamismo social e econômico. A desigualdade entre os indivíduos em uma sociedade de mobilidade aberta faz com que esta sociedade tenha um dinamismo extraordinário. [...] Mas, existe uma conotação negativa, na medida em que a desigualdade, ao crescer, diferenciando os homens, coloca em risco a construção do espaço da igualdade. Esta conotação negativa é mais manifesta quando grupos sociais são colocados no espaço da pobreza absoluta e, sobretudo, na fronteira da sobrevivência, pois, assim, ficam impossibilitados de participar da gestão dos bens comuns.
\end{abstract}

Dessa forma, a partir da perspectiva estudada pela Escola de Chicago, concentramos nossa preocupação quanto a relação entre as áreas denominadas degradadas, que sofrem influência direta dos citados fatores - pobreza, exclusão e desigualdade social - com o problema da criminalidade, especificamente a de caráter violento, no âmbito da juventude.

\title{
2 TEORIA DA ECOLOGIA HUMANA : CRIMINALIDADE, DESVIO E DESORGANIZAÇÃO SOCIAL
}

A Teoria da Ecologia Humana, passando a ser compreendida como uma alternativa às teorias que explicavam o comportamento humano como decorrente de uma esfera meramente psicogenética, surge na defesa da ideia de que o ambiente exerce influência no comportamento humano, levando-se em consideração fatores sociais, econômicos, políticos, culturais etc., como já salientado antes. De maneira que, diferentes áreas da cidade, por encontrarem-se em situações díspares, não só geograficamente, muitas vezes acabam se transformando, ainda que transitoriamente, em ambientes degradados, esquecidos e marginalizados, constituindo-se verdadeiros locus do não exercício de direito à cidade, no sentido defendido por David Harvey (2008: 74), para além do acesso aos recursos urbanos, também implica falar da liberdade de construir e reconstruir a cidade e a nós mesmos - o que o autor enxerga como um dos direitos humanos mais negligenciados.

Então, com base na noção da desorganização social, nota-se que não são puramente as intenções que sujeitam o indivíduo ao crime, pois, na verdade, trata-se também de uma questão de crise nos mecanismos de controle social, principalmente o informal, isto é, os laços sociais comunitários ${ }^{4}$. Nessa linha de pensamento, um importante fator defendindo pela

\footnotetext{
${ }^{4}$ Encontramos essa perspectiva no pensamento de Shecaira, quando nos ensina que existem duas instâncias de controle social: a informal, que perpassa pela sociedade civil: família, escola, profissão, opinião pública, grupos de pressão, grupos de serviço, etc; e a outra instância é a do controle social formal: observada como aquela
} 
Escola de Chicago é a força da comunidade de se auto-organizar e prevenir seus problemas sociais de modo endógeno. Portanto, um ambiente escasso de recursos que sustentem uma vida minimamente digna, agravado pela grande mobilidade de pessoas, ocasiona o enfraquecimento das instituições básicas da sociedade - como a família, a escola, dentre outras. Assim, uma vez fragilizados, esses indivíduos tornam-se potencialmente suscetíveis à perda de objetivação social; saliente-se, que o grande anseio dos que habitam essas áreas degradadas, nada mais é do que deixar tal situação, canalizando todos os seus esforços para uma modificação de tal realidade.

$\mathrm{Na}$ Teoria das Zonas Concêntricas, de Burgess, é traçada a Zona II - justamente o espaço mais degradado da cidade de Chicago, como a área mais potencialmente criminogênica. Sobre essa zona, enfatiza Freitas (2002, p. 75):

\begin{abstract}
A Zona II, normalmente, é marcada por casas em péssimo estado de manutenção, infra-estrutura deficiente, pobreza, doenças, alcoolismo, restaurantes baratos, pessoas ociosas, novos imigrantes e baixo controle social. É a "área natural" a ser ocupada pelo recém-chegado à cidade, por ser a mais barata para se viver e se localizar próxima das fábricas, que absorvem esta mão-de-obra. Ali residem pessoas de classes desfavorecidas e minorias, sendo local propício ao desenvolvimento de cortiços e formação de guetos. Por estas razões, é considerada a área mais indesejada para se morar, o que explica a alta mobilidade residencial que a caracteriza.
\end{abstract}

Mas, muito embora a teoria da Ecologia Humana esteja apoiada na ideia de desorganização social, a constatação feita dentro das comunidades é de que cada uma delas possui uma estrutura, seguindo até mesmo níveis de hierarquia, tendo em vista que "todo grupo de excluídos tende a desenvolver práticas de solidariedade interna, para se proteger das representações negativas do restante da sociedade." (NASCIMENTO, 2003, p.60). Logo, o desafio passa a ser a promoção do redirecionamento das práticas ali existentes, procurando preservar o espírito de aliança que eventualmente tenha se formado.

Ainda nesse contexto, destacamos que os estigmas em cima das classes pobres relacionam-se a diferentes padrões históricos e culturais de cada região do mundo. $\mathrm{Na}$ realidade latino-americana, notamos que a rápida urbanização tem o poder de substituir as relações sociais primárias pelas secundárias, de menor controle social; sendo que esta situação

esfera de atuação do aparelho político estatal. Cf. SHECAIRA, S. S. Criminologia. 5.ed. São Paulo: Revista dos Tribunais, 2013. Passim. 
se agrava pelo fato de vivermos em uma sociedade onde o apelo ao consumo é veemente, tensionando ainda mais os trabalhadores pobres. De modo que essa dinâmica concorre para o crescimento da violência urbana e das novas representações sociais sobre os pobres, onde, muitas vezes, é por meio da violação da transgressão da lei que irá se buscar resolver tais tensões. (NASCIMENTO, 2003, p.70).

Na medida em que as relações são cada vez mais transitórias, como também o controle social informal menos presente, os valores comunitários aos poucos também vão ficando mais fragilizados,auxiliando no processo do surgimento de agrupamentos considerados desviantes. Em outros termos, o que acontece é uma substituição de valores e a consequenteconfiguração de uma nova ética dentro daquela realidade; ou seja, enquanto esses grupos ocupam espaços por intermédio de um determinado poder exercido naquela comunidade, estimulam igualmente a formação de novos grupos desviantes. Assim, muitos irão, de fato, constituir família, conseguir uma moradia, arrumar um emprego - ainda que em condições miseráveis - mas já outros não terão outra alternativa e permanecerão na criminalidade.

Para a Ecologia Humana, o fator pobreza é um elemento considerável, uma vez que os integrantes desta classe são levados a habitar as regiões mais degradadas, onde, na maioria dos casos, moram também os autores de infrações criminais, como ressalta Tangerino (2002). Dessa maneira, observa-se que os novos moradores nem sempre seguirão o caminho dos que ali já estavam; contudo, a experiência nos mostra que a parcela jovem, principalmente os filhos de pessoas pobres, influenciados por esses ambientes, estarão sujeitos à interação com uma gama de condutas, abrangendo, infelizmente, a criminal.

Diante dessas considerações, percebemos que uma constatação feita pela Escola de Chicago reside no fator do fortalecimento do controle social informal, por meio dos grupos sociais e da comunidade, restabelecendo a perspectiva dos laços comunitários. Com efeito, essa alternativa encontra justificativa na relação mútua existente entre um controle social frágil (em virtude da perda da coesão moral) e o crescimento da desorganização social, haja vista que essa interação, segundo os ecologistas sociais, é capaz de promover e agravar os níveis de grupos desviantes, de criminalidade, sobretudo a juvenil, nas áreas deterioradas.

$\mathrm{Na}$ convivência em sociedade, é pacífico que todos os grupos sociais estabeleçam regras, seguindo preceitos morais e políticos. Por conseguinte, o indivíduo que violar essas 
normas, quebra um contrato social, maculando, então, uma situação de estabilidade, de normalidade. Segundo Becker (2008, p. 27):

\begin{abstract}
Regras sociais são criações de grupos sociais específicos. As sociedades modernas não constituem organizações simples, em que todos concordam quanto ao que são regras e como elas devem ser aplicadas em situações específicas. São, ao contrário, altamente diferenciadas ao longo de linhas de classe social, linhas étnicas, linhas ocupacionais e linhas culturais. Esses grupos não precisam partilhar as mesmas regras e, de fato, frequentemente não o fazem. Os problemas que eles enfrentam ao lidar com seu ambiente, a história e as tradições que carregam consigo, todos conduzem à evolução de diferentes conjuntos de regras. À medida que as regras de vários grupos se entrechocam e contradizem, haverá desacordo quanto ao tipo de comportamento apropriado em qualquer situação dada.
\end{abstract}

Assim, dependendo do teor da ruptura dessas regras, bem como da conjuntura social de um determinado local, aplica-se uma penalidade como forma de compensação por tal ato; a essa conduta de transgressão, dá-se o nome de infração penal, que abrange as contravenções penais e os crimes. Segundo Capez (2009, p. 113), o crime pode ser considerado "como todo fato humano que, propositado ou descuidadamente, lesa ou expõe a perigo bens jurídicos considerados fundamentais para a existência da coletividade e da paz social.” A contravenção penal trata-se de uma conduta de menor potencial ofensivo punida, no nosso ordenamento jurídico, com prisão simples, multa ou com ambos; já o crime, abrange os fatos típicos considerados mais graves, os quais o nosso Código Penal pune com detenção ou reclusão, podendo cumular ou não com multa.

Lembremos como o delito é tratado de maneiras diferentes pelo Direito Penal e pela Criminologia. Shecaira (2013, p. 43) destaca que para o Direito, o conceito de crime aponta “para um juízo de subsunção do fato à norma, juízo esse que é puramente individual”. O autor afirma que a Criminologia trata o crime para além dessa noção: observa o crime como fenômeno comunitário e como um problema social e questiona os fatores que levam os indivíduos a promover um fato humano corriqueiro à condição de crime.

No que tange ao Direito Penal e às políticas criminais, em regra, os indivíduos que transgridem a lei, especificamente aqueles que cometem os atos de maior potencial ofensivo, ou seja, de maior reprovação social, tendo em vista que atingem valores e bens essencialmente relevantes, são os chamados criminosos, sendo pessoas que se desviaram de uma dinâmica socialmente desejável. 
Quanto ao vocábulo desvio, segundo o dicionarista Aurélio Buarque Ferreira de Holanda (2001), é o ato de desviar(-se) da posição normal. Logo, é a partir desta perspectiva de raciocínio que os sociólogos de Chicago contextualizaram tal acepção nos estudos sobre criminalidade, buscando as causas de condutas consideradas atípicas, que direcionem seus efeitos para uma vertente anormal dentro de uma determinada sociedade. Registre-se, que o conceito sociológico de desvio não se exaure nas pesquisas sobre o crime, pois é encontrada sua aplicação em diversos outros temas, sendo que, no presente trabalho, nos limitaremos àquela área específica destacada antes.

Por muito tempo, houve uma certa tendência em atribuir as raízes da conduta criminosa a fatores biológicos e psicológicos. Em conformidade com Miskolci (2005, p.12), os cientistas viam no lugar do desempregado o "vagabundo", sendo o criminoso compreendido como um anormal nato, ao invés de alguém que envereda pelo crime devido a circunstâncias sociais. O desvio, pois, era tido como doença e, por conseguinte, o desviante, um degenerado.

Desde o final do século XIX, com a Teoria da Ecologia Humana, apoiando-se, basicamente, em uma analogia entre a acepção biológica e a organização estrutural da sociedade, de um modo geral, as pesquisas passaram a tomar outro rumo, com fundamento na ideia da desorganização social, respaldando seus estudos no conceito de ambiente degradado, levando em consideração fatores culturais, econômicos, entre outros, como já ressaltado anteriormente.

No âmbito deste trabalho, consideramos os jovens envolvidos com o crime como personagens desviantes, tomando a concepção de desvio na sua versão mais aproximada da noção de exclusão, como um dos desdobramentos desta - por um ordenamento socialmente instituído -, procurando observar o impacto que a pobreza, a exclusão e as desigualdades sociais relacionadas a ambientes degradados ocasionam na faixa etária das pessoas jovens.

Indiscutivelmente, esse conjunto de elementos concorre para um agravamento da sujeição ao crime, principalmente devido aos estigmas que abrangem os integrantes das classes menos favorecidas, para os quais, nem a justiça, nem tampouco as políticas públicas, atuam de modo eficaz. A respeito dessa realidade, Becker (2008, p. 25), baseado nos ensinamentos mertonianos, esclarece-nos o seguinte: 
O grau em que um ato será tratado como desviante depende também de quem o comete e de quem se sente prejudicado por ele. Regras tendem a ser aplicadas mais a algumas pessoas que a outras. Estudos da delinquência juvenil deixam isso muito claro. Meninos de áreas de classe média, quanto detidos, não chegam tão longe no processo legal como os meninos de bairros miseráveis. O menino de classe média tem menos probabilidade, quando apanhado pela polícia, de ser levado à delegacia, de ser autuado; é extremamente improvável que seja sentenciado. Essa variação ocorre ainda que a infração original da norma seja a mesma nos dois casos [...].

A título de ilustração, dentro da realidade brasileira, podemos fazer uso até mesmo da nossa literatura, citando a célebre obra de Jorge Amado, “Capitães da Areia” que, em 1937, já criticava e retratava essa problemática das desigualdades jurídica e social com que nossos cidadãos são tratados, mostrando-nos a situação de estigma que os jovens, principalmente os mais carentes, viviam e ainda vivem na época atual. A narrativa deste autor tem início com a notícia de um jornal alertando a população para o seguinte fato:

O que se faz necessário é unia urgente providência da policia e do juizado de menores, no sentido da extinção desse bando e para que recolham esses precoces criminosos, que já não deixam a cidade dormir em paz o seu sono tão merecido, aos Institutos de Reforma de crianças ou às prisões. Passemos, agora, a relatar o assalto de ontem, do qual foi vítima um honrado comerciante da nossa praça, que teve sua residência furtada em mais de um conto de réis e um seu empregado ferido pelo desalmado chefe dessa malta de jovens bandidos [...].

É certo que, diante do contexto de um ambiente degradado, não podemos generalizar o caso, afirmando que todos os jovens ali residentes serão criminosos. Em resumo, que fique clara nossa ideia de que os jovens são consideravelmente atingidos pelos problemas que existem nesses ambientes no que concerne ao aspecto da criminalidade.

Ressalte-se, também, o fato de que a teoria desenvolvida pela Escola de Chicago foi construída sob a égide de um contexto sócio-cultural presente naquela região específica, submetida a um determinado processo histórico. Até mesmo no que diz respeito à estrutura espacial da cidade, na Teoria das Zonas Concêntricas de Burgess, há de se fazer, evidentemente, sua devida adaptação, caso se queira aplicá-la à realidade brasileira. Assim, com as devidas ressalvas, valemo-nos dos conceitos e ideias ecológicas a fim de buscarmos a adequada compreensão da nossa temática, sem, contudo, exauri-la.

Diante do exposto, verificamos o desvio esteriotipado em uma situação de conflito, onde os desviantes não compõem a integralidade de um grupo social formado pelos jovens, sendo eles pessoas que, influenciados pelos fatores já mencionados, dão sua resposta à 
desorganização social - naturalmente proveniente do processo urbano - a qual se encontram inseridos e submetidos as suas consequências mais graves. Portanto, são indivíduos considerados, pela parcela "normal" da sociedade, como incômodos ou mesmo "nãopessoas", já excluídos automaticamente pelas circunstâncias sociais que vivenciam. De fato, são vítimas e eventualmente autores, sobretudo, da violência urbana, sendo que não deveríamos desconhecer tal invisibilidade, tendo em vista que também participamos desse processo. Enfim, somos responsáveis, em maior ou menor escala, pelo sistema social no qual estamos submetidos, onde inúmeras pessoas, pouco a pouco, perdem até mesmo a própria noção de humanidade. ${ }^{5}$

Com efeito, a partir dos estudos que desenvolveram a teoria da desorganização social nos ambientes degradados como um relevante fator causal da criminalidade, os sociólogos de Chicago, liderados por Clifford Shaw, em 1930, pensaram em um projeto onde pudessem testar suas teorias mais a fundo, objetivando o fortalecimento do que eles acreditavam como sendo importantes elementos na comunidade: o reatamento dos laços sociais comunitários e uma maior concretude dos instrumentos de controle social informal. Dessa maneira, é criado o Chicago Area Project, como já salientamos antes, cuja principal finalidade se encontrava na promoção de oportunidades e conscientização da população local, no sentido de prevenir e combater os problemas da criminalidade partindo de seus próprios esforços; de fato, o ideal de reforma social do qual fizemos menção é, necessariamente, defendido neste projeto.

Assim, o Chicago Area Project foi inicialmente estabelecido na comunidade de Russel Square Park, no sul da cidade de Chicago, área considerada intensamente degradada, devido a sua localização circunvizinhada por indústrias, onde a maioria dos seus habitantes trabalhava em condições precárias, sob uma carga horária semanal de 60 horas, dedicando, portanto, pouco ou nenhum tempo às atividades familiares e comunitárias (TANGERINO, 2007, p. 94). Nessa conjuntura urbana, os níveis de delinquência juvenil eram marcantes na Russel Square, área urbana na qual o Chicago Area Project concentrou seus objetivos de prevenção do crime e tratamento dos delinquentes. Os princípios e a filosofia deste projeto voltavam seus olhares especialmentepara dentro das casas desses jovens. Nessa perspectiva, Sorrentino (1959, p.40) lembra que, para os seus fundadores, o Chicago Area Project:

\footnotetext{
${ }^{5}$ Nesse sentido, Hannah Arendt, a partir da Origens do Totalitarismo e de A Condição Humana, discute a perda da noção de humanidade por determinados grupos sociais em situações de exceção e exclusão. Cf. ARENDT, H. A Condição Humana. 11. ed. Rio de Janeiro: Forense, 2010; antissemitismo, imperialismo, totalitarismo. São Paulo: Companhia das Letras, 2013. As Origens do Totalitarismo:
} 
[...] era a esperança de que um método mais efetivo para a prevenção da delinquência e do tratamento de delinquentes nas áreas economicamente pobres e fisicamente deterioradas da cidade poderia ser desenvolvido por intermédio dos esforços organizados dos moradores dessas áreas. O programa é baseado na convicção de que os residentes locais - os pais, as mães e os líderes nativos constituem o ambiente humano primário da criança e do mundo social significativo, por meio do qual ela é socializada. (tradução nossa) ${ }^{6}$

Ademais, os espaços de socialização na comunidade em estudo acabam sendo principalmente as tavernas, onde as pessoas se juntavam para consumir bebidas alcoólicas, havendo inúmeros desses estabelecimentos, e o breve período de tempo que os residentes dessa área tinham, era dedicado a tais lugares. Realmente, a ausência de ambientes e atividades que contribuissem de maneira positiva na construção de uma comunidade menos desorganizada socialmente também enfraquecia os laços sociais e o controle social informal.

Então, levando-se em consideração toda essa realidade social, o Chicago Area Project intervém no Russel Square Park com três propostas claras de atuação: recreação, vigilância e mediação (TANGERINO, 2007, 99). Nesse sentido, Clifford Shaw era avesso às atividades meramente assistencialistas, vislumbrando o desenvolvimento de habilidades já potencialmente construídas naquela comunidade, mas que precisavam ser redirecionadas para uma vertente positiva e, para isso, o esporte era visto como um meio eficaz, entre outras atividades oferecidas na comunidade, mormente à faixa etária jovem. De forma que tudo isso conservava a ideia de união, de time - já contida nas gangues, por exemplo -, mas também estimulava valores como disciplina e respeito, além de desencorajar a agressão.

De modo igual, o envolvimento da família nas atividades desses jovens era extremamente visado e fomentado pelo programa, pois observava-se "que a delinquência juvenil como fenômeno social continha em si um elemento de ausência de supervisão paterna [...] O processo educativo é uma das formas essenciais de exercício do controle social informal" (TANGERINO, 2007, p. 101). O projeto, inclusive, acreditava que a escola, enquanto instituição social, obteria resultados mais significativos na medida em que a

\footnotetext{
${ }^{6}$ Esta perspectiva é apresentada no artigo publicado na Federal Probation, onde Sorrentino desenvolve uma retrospectiva social, cultural, política e econômica do referido projeto. Cf. SORRENTINO, A. The Chicago Area Project after 25 years. In: Federal Probation. Washington, DC: Administrative Office of the U.S. Courts, v. 23, June, 1959.
} 
comunidade a compreendesse como integrante dela, e não apenas como um organismo autônomo.

$\mathrm{Na}$ realização e promoção das diversas atividades, o programa contava impreterivelmente com o auxílio de instrutores locais - líderes natos da própria comunidade que conheciam de fato a linguagem, o comportamento e a dinâmica dos moradores, facilitando a aplicação dos princípios, mediando os jovens e contribuindo bastante no estímulo à participação de mais residentes no projeto. Sobre esse ponto de vista, Sorrentino (1959, p.40) é bem elucidativo:

\begin{abstract}
Este método de auto-ajuda cooperativa para os problemas da comunidade local tem sido um poderoso estímulo aos residentes. Recursos humanos até então inexplorados no bairro são mobilizados para um ataque concentrado e coletivo sobre os problemas humanos. Os cidadãos e os líderes locais conhecem sua comunidade intimamente, têm contatos e relações significativos com o mundo social e pessoal do delinqüente e podem, portanto, fazer uma contribuição distinta para a solução de problemas locais. (tradução nossa) ${ }^{7}$
\end{abstract}

De fato, os programas do Chicago Area Project eram distintos dos já realizados por outras agências, pois se dispuseram a enfrentar o desafio de trabalhar com jovens delinquentes, os quais necessitavam de atenção redobrada; sendo que esta seria fomentada pelo projeto nos habitantes locais do Russel Square Park. Além disso, tal projeto também prestou importante atenção à intervenção na vida das crianças, procurando inibir condutas que posteriormente entrariam em conflito com a comunidade e com a lei. Em relação a isso, Schlossman et al (1984, p. 17) explica:

[...] Uma das características mais importantes que distinguiram o Chicago Area Project de outras agências sociais era a sua vontade de trabalhar com jovens persistentemente difíceis e delinqüentes. [...] O CAP não virou as costas para jovens mais velhos que, por uma razão ou outra, ignoraram o conselho de funcionários e voluntários e persistiram na conduta criminosa ao ponto onde foram cometidos para reformar escolas e prisões. A lógica do projeto, na verdade, o obrigava a fazer esforços especiais para incorporar o jovem adulto ex-presidiário em programas do CAP [...].(tradução nossa) ${ }^{8}$

\footnotetext{
${ }^{7}$ Encontramos a concepção de "auto-ajuda cooperativa", de igual modo, no artigo elaborado por Sorrentino, quando destaca a relevância de tal método para a solução dos problemas verificado em determinadas comunidades. Cf. SORRENTINO, 1959.

${ }^{8}$ Sobre a ideia preventiva da criminalidade, Schlossman desenvolve uma relevante abordagem no âmbito da intervenção na vida das crianças, no sentido de prevenir práticas que posteriormente poderiam entrar em conflito com a lei. Cf. SCHLOSSMAN, S. SHAVELSON, R. ZELLMAN, G. Delinquency prevention in south Chicago: a fifty-year assessment of the Chicago Area Project. Santa Monica, C.A; Rand, May, 1984.
} 
Após essas reflexões, foi possível compreender o Chicago Area Project é como sendo um bom modelo para o nosso estudo, até porque ele tem obtido resultados desejáveis e significantes, haja vista que os indíces de delinquência entre os jovens decaíram, ainda que tal fato não esteja meramente relacionado à intervenção de Shaw e sua equipe (TANGERINO, 2007, p. 109). De maneira que, podemos atribuir o sucesso do projeto, entre outros fatores, ao caráter do trabalho direto com e para a comunidade, pois a mudança em grande escala, isto é, na cidade como um todo, obviamente começa nas suas parcelas, e, para isso, é fundamental a participação dos moradores de cada área.

\section{CRIMINALIDADE: O CENÁRIO BRASILEIRO DOS HOMICÍDIOS NA FAIXA ETÁRIA JOVEM}

No tópico anterior, salientamos que em um ambiente degradado, devido à escassez de recursos e fragilidade do controle social, a parcela mais atingida, sobretudo pela violência urbana, é a da população jovem - compreendida a faixa etária entre 15 e 29 anos. ${ }^{9}$ Realmente, haja vista que própria comunidade onde estes jovens estão inseridos encontra-se com suas instituições fragilizadas, comprometendo os referenciais mais básicos da vida em sociedade (família, escola, vizinhança etc), em virtude de fatores sociais, culturais, econômicos, dentre outros, levam essas pessoas a buscarem a sensação de pertencimento em outro loco. Assim, o futuro que terão, muitas vezes, estará diretamente associado a uma realidade de violência, criminalidade e exploração.

Saliente-se, também que, muito embora este grupo social esteja formalmente inserido no arcabouço jurídico, sob a égide dos direitos e garantias fundamentais, percebemos, principalmente nas camadas financeiramente carentes da sociedade, uma considerável ineficácia dos programas sociais específicos voltados à proteção familiar e à convivência comunitária. Por conseguinte, a vulnerabilidade desses jovens, para além dos seus reclames intrínsecos, nada mais é do que o próprio reflexo da fraqueza dos vínculos sociais e pessoais desenvolvidos; de forma que os esforços dessas políticas sociais devem ser direcionados no sentido de propor o fortalecimento desses laços, trabalhando a questão de maneira centrífuga, tendo em vista que a comunidade é o loco primário das sociabilidades em grande escala.

\footnotetext{
${ }^{9}$ Esta faixa etária em conformidade com a definição incluída no Art. $1^{\circ} \S 1^{\mathrm{o}}$ do Estatuto da Juventude estabelecido pela Secretaria Nacional de Juventude (disponível em http://www.secretariageral.gov.br/Juventude acesso em 10 de janeiro de 2014)
} 
Na formação dos novos grupos sociais, observamos o conceito de gangue como sendo um conjunto de jovens, residentes na mesma vizinhança, os quais, regularmente, praticam diversas atividades, que vão desde pequenas contravenções chegando até mesmo a crimes de maior potencial ofensivo (FREITAS, 2002, p.79). Tal fenômeno está relacionado com a procura de uma identidade em função da configuração que a cidade tem, representando, assim, uma alternativa ao que a sociedade lhes rejeita; ou seja, trata-se de um grupo onde os jovens integrantes têm a uma sensação de pertencimento, que compõem algo.

Na concepção de Einstadter \& Henry apud Freitas (2002, p.70), a prática de infrações penais pelos membros da gangue, para a Teoria da Ecologia Humana, é consequência da busca pela sobrevivência em ambientes socialmente desorganizados. De maneira que, a associação é um fenômeno comum, principalmente na fase da juventude, onde se busca identidade, assimilação, entre outras particularidades; de igual modo, isso também acontece nos ambientes degradados, porém, são as condutas desses grupos que refletem os problemas que atingem a comunidade onde vivem.

Com efeito, o anseio por espaços públicos é frequentemente verificado, sendo estes locais necessários. Nesse contexto, várias pesquisas realizadas em municípios brasileiros revelaram o desejo das pessoas de terem locais abertos, no intuito de possibilitar a interação com a comunidade, tais como praças, parques etc. Em um estudo desenvolvido no Distrito Federal, Abramovay et al (2002, p.49-50) afirmam:

\begin{abstract}
A vida na periferia impõe uma existência marcada pela rotina, com graves limitações às atividades de lazer, seja por precárias condições de infra-estrutura das cidades, seja em virtude da falta de dinheiro. De fato, esses jovens contam com poucas possibilidades de diversão, de praticarem esportes e de utilizarem, de maneira geral, as suas criatividades. Frequentemente, restam poucas alternativas, além da prática de atos ilícitos e do consumo de drogas e bebidas alcoólicas que, ao mesmo tempo, representam uma forma de diversão e, por outro lado, são constitutivos de um ambiente de violência que coloca novas restrições ao exercício do lazer.
\end{abstract}

Como podemos constatar, além da escassez de estruturas e programas eficazes que fomentem a socialização nesses ambientes degradados, uma determinada área pode também configurar-se como criminogênica, mesmo com a constante mobilidade de seus habitantes, sendo a partir dessa perspectiva que a ecologia humana atenta para o fortalecimento dos laços comunitários. Para explicar como isso acontece, Shaw e McKay construíram a teoria da delinquência por transmissão cultural. Assim, são nos ensinamentos de Freitas (2002, p.85) que esta proposta teórica torna-se bastante clara: 
O ponto-chave é que certos tipos de crime se tornavam uma norma cultural dentro da zona de transição. Eles relacionaram a delinquência juvenil à teoria de desorganização social. Afirmavam que havia uma probabilidade maior da prática de crime numa comunidade com ausência de suporte comunitário, havendo probabilidade menor de sua ocorrência se os adolescentes tivessem apoio de seus pais, escola e/ou igreja. A alta mobilidade verificada na área central da cidade fazia com que os residentes tivessem uma tendência a não se interessarem pelo que ocorria à sua volta, já que não pretendiam ficar ali por muito tempo.

Após essa explanação genérica sobre a Teoria da Ecologia Humana, passaremos a demonstrar algumas implicações desta perspectiva no âmbito de sua relação entre criminalidade e juventude na realidade social brasileira.

A expressão violência urbana é bem ampla, pois envolve inúmeras formas de condutas praticadas no contexto das cidades, podendo ser exteriorizada por meio do exercício do constrangimento, físico ou moral, sobre alguém, no sentido de obrigá-la a submeter-se à vontade de outrem; ou, ainda, podem, igualmente, ser utilizadas contra a liberdade de um bem material. Por conseguinte, de imediato, lembramos do furto, roubo, sequestro, homícidio, entre tantas outras situaçõe; mas, sem dúvida, um dos crimes que mais abalam o imaginário coletivo é o assassinato, sendo exatamente para este que voltaremos nossa atenção, principalmente devido ao fato dos alarmantes indíces envolvendo jovens brasileiros.

O grupo social de faixa etária jovem, especialmente aqueles que vivenciam uma realidade desprovida de recursos materiais e simbólicos, com pouco ou nenhum acesso às estruturas de oportunidades sociais, econômicas, culturais encontram-se em condição de vulnerabilidade. Então, as lacunas deixadas pelas esferas convencionais de sociabilidades desencadeiam vários problemas para esses jovens, visto que são potencializadoras da característica recorrente da transgressão. Logo, a compreensão do fenômeno da violência é um dos maiores desafios contemporâneos (ABRAMOVAY, 2003, p.1).

O cenário da violência no Brasil revela que tal fenômeno não é consequência pura da diversidade do nosso povo, haja vista que o principal fator que contribui para o agravamento da situação é o da exclusão social, onde muitas pessoas já não são mais vistos como tais por seus semelhantes (NASCIMENTO, 2003, p.56). Em consequência disso, a transgressão por meio da violência surge como uma resposta à dura realidade vivida, como bem elucida Cara $\mathrm{e}$ Gauto (2007, p.180):

O problema fundamental não está na existência e convívio de diferentes grupos, mas na maneira como a dinâmica social vivida no Brasil gerou, e permanentemente reproduz, um ciclo perverso de exclusão social que, se considerarmos a questão da 
violência, gera preconceito e tem como conseqüência perigosa a negação de direitos para a população excluída - em relação à juventude, resulta no não-reconhecimento da condição de sujeito de direitos. A violência aparece aí não só como um sintoma da convulsão social, mas também como uma eficaz, embora triste, maneira de comunicar à sociedade essa degradação social e comunitária. Contudo, as vítimas da violência urbana têm o mesmo perfil de seus agressores [...].

Em pesquisa realizada por Tangerino (2007, p.127-130), sobre a criminalidade na cidade de São Paulo, utilizando-se dos conceitos ecológicos mencionados neste texto, foi observado uma relação de proporção direta, em diversos bairros, entre o número de chefes de domicílios pobres e mortes violentas, sendo que o inverso também é verificado; ou seja, quando a pobreza diminui também reduzem os números de homicídios. Além do fator econômico, elementos como mortalidade infantil, acesso aos meios de locomoção, desemprego, entre outros também estão relacionados a tal fato. Nessa perspectiva, registre-se que não apenas no estudo anteriormente destacado, mas também no quadro geral de homicídios do nosso país, verifica-se que a maior parcela atingida é composta pela faixa etária jovem.

Mas, diante de tais evidências, surge o seguinte questionamento: por quê tudo isso ocorre mais frequentemente com os jovens e não com os mais velhos? Sem dúvida, o momento vivenciado pela juventude se diferencia das demais faixas etárias na medida em que ocorre uma verdadeira busca por identidade e auto-afirmação; de maneira que a grande maioria dos jovens é assim, não importando a classe social em que estejam inseridos. Porém, essa fase, nas camadas mais carentes da sociedade, se distingue na exteriorização dessa busca, refletindo-se, muitas vezes, por intermédio da violência. Nessa linha de raciocínio, Cara e Gauto (2007, p.180-181) esclarecem que:

\begin{abstract}
A violência aparece também como um recurso à preservação da auto-imagem: ser violento e/ou envolvido com a criminalidade confere status social. A vida social compartilhada em grupos é fundamental para o jovem, pois oferece apoio e proteção. A violência, enquanto afirmação de identidade, necessita de uma platéia, já que comunica, ao se romperem as regras e recorrerem à violência, quem é e o lugar que quer ocupar. Em São Paulo, uma característica fundamental e peculiar dos casos de homicídios é que estes são resultados de conflitos interpessoais, tendo como autor pessoas sem antecedentes criminais e que são, geralmente, conhecidos das vítimas. O problema dos homicídios de jovens tem muito mais a ver com a maneira como os conflitos são resolvidos do que com o envolvimento com a criminalidade. Fatores como machismo, a expressão de poder dentro de um grupo e a honra têm a função de tencionar os conflitos a soluções violentas.
\end{abstract}

Carla Coelho de Andrade (2007, p.133-136), em um recente trabalho realizado nas periferias de Brasília, afirma que a proximidade com a violência nos ambientes degradados 
banaliza o comportamento violento, tornando-o, com frequência, trivial; de forma geral, os jovens acreditam que há sempre uma justificativa para que a pessoa exerça a violência, sendo esta considerada por eles como legítima nos seguintes casos: extrema pobreza; necessidades básicas e desemprego; sentimento de vingança; uso de drogas; entre outros que também fazem parte dessa percepção.

Há aproximadamente 15 anos, no âmbito nacional, vem sendo desenvolvida uma pesquisa que pode nos auxiliar a ter uma noção mais precisa da situação de homicídios envolvendo jovens, sobretudo na condição de vítimas, que é o denominado Mapa da Violência (WALSELFISZ, 2014), onde se dedica uma parte especial voltada aos estudos sobre a juventude. O mapa mais recente, disponibilizado em 2014, traça o quadro dessa realidade, de modo que elaboramos um resumo das últimas décadas, com o intuito de demonstrar o preocupante percentual de homicídios - considerados genericamente como aquelas agressões intencionais por terceiros que levam à morte da vítima - dentre os óbitos da população jovem, em comparação a dos não jovens:

Tabela: Estrutura da Mortalidade: Número de Homicídios (por 100 mil). População Não Jovem e Jovem. Brasil, 1980/2012 (adaptado)

\begin{tabular}{lcccc}
\hline População & Não Jovem & \multicolumn{2}{c}{ População Jovem } \\
\hline Ano & Total de Óbitos & Homicídios & Total de Óbitos & Homicídios \\
\hline $\mathbf{1 9 8 0}$ & 828,7 & 8,5 & 146,6 & 19,6 \\
\hline $\mathbf{1 9 9 0}$ & 727,5 & 14,7 & 158,3 & 41,2 \\
\hline $\mathbf{2 0 0 0}$ & 718,3 & 16,7 & 148,8 & 52,3 \\
\hline $\mathbf{2 0 1 2}$ & 778,4 & 18,5 & 148,9 & 57,6 \\
\hline
\end{tabular}

Fonte: SIM/SVS/MS

A tabela demonstra um crescimento de $194,2 \%$ no número de homicídios de jovens entre os anos de 1980 e 2012. de Ademais, a própria relação direta, entre o número total de óbitos e de homicídios, nos causa uma certa inquietação: o homicídio foi responsável por $28,8 \%$ da morte de jovens nesse período. Isto é um indicativo que a juventude vem sendo vítima em uma escala crescente. 
Sem dúvida, somente no ano de 2011, o número de homicídios de jovens brasileiros ultrapassa o das mortes diretas em batalhas armadas durante 4 anos no Afeganistão, por exemplo; em período igual a este, 62 conflitos armados ao redor do mundo resultaram em um total de 208.349 mortes diretas, total este que não supera o número de jovens vítimas de homicídio em 12 anos (2000-2011) no Brasil, país onde não há disputas territoriais, movimentos emancipatórios,conflitos de fronteiras ou atos terroristas, entre outros (WALSELFISZ ,2013, p. 21).

Em uma outra dimensão, Cara e Gauto (2007, p.175) observam uma certa correlação entre o protagonismo juvenil nos indíces de criminalidade e os fatores como a baixa do crescimento econômico, notadamente desde 1980; além disso, esses autores igualmente destacam a queda dos investimento em infra-estrutura, como também das políticas sociais, tudo isso em prol da valorização do mercado produtivo no lugar do financeiro. Continuando, os referidos autores consideram que as taxas de desemprego e homicídios são mais presentes entre os jovens devido à vulnerabilidade destes, comparada a dos mais adultos. Nesse ponto de vista, reiteramos que esse aspecto decorre da ambientação degradada que a juventude, principalmente a das classes menos favorecidas, vivencia, relacionada à precariedade dos instrumentos de controle social informal (apoio e supervisão familiar, convivência comunitária, educação escolar de qualidade etc). Porém, saliente-se que esse fenômeno pode ser amenizado com o fortalecimento do capital social, sendo este entendido, segundo Putnam (2000, p. 177) como as redes e os laços existentes entre os habitantes de uma determinada sociedadade, no sentido de coordenar as suas ações.

Logo, a família, a comunidade e a escola necessitam de um olhar atento por parte das políticas públicas e da sociedade como um todo. Ademais, o Estado não deve procurar apenas substitur tais instituições, que são básicas, por outras, devendo sim promover oportunidades adequadas que as levem a dialogar social, cultural e economicamente com toda a cidade de maneira harmoniosa. Indiscutivelmente, esse caráter intersetorial é de imensa importância, na medida em que o todo irá direcionar seus esforços para pontos em comuns, ou seja: o fortalecimento da comunidade, a proteção dos cidadãos e a redução dos ambientes hostis, bem como do caráter criminogênico das áreas mais degradadas.

\section{CONSIDERAÇÕES FINAIS}


Ao término deste trabalho, observamos que os estudos desenvolvidos pela Escola de Chicago são de grande importância na compreensão dos fenômenos que surgiram ao longo da estruturação das cidades, sobretudo das metrópoles. Neste texto, nossa pretensão não foi apenas de relacionar as principais teorias dos sociólogos de Chicago, visto que nos propomos a analisar as articulações entre as ideias propostas nas teorias e as soluções que foram encontradas, sempre buscando despertar a reflexão sobre a necessidade de integração entre as várias áreas afins do saber científico, notadamente no campo das ciências sociais aplicadas.

No decorrer deste estudo, percebemos que as causas isoladas não são suficientes para elucidar as problemáticas que foram suscitadas; de modo que a pobreza, a desigualdade social, a exclusão e a degradação urbana são resultados de processos econômico, cultural, político, entre outros, que predominam nas sociedades capitalistas. Assim, o encontro dessas iniquidades sociais com tais processos formam e disseminam fenômenos sociais preocupantes, destacando-se entre estes a criminalidade, que na época atual assola o nosso país de maneira ascendente.

Concluiu-se também que no âmbito da criminalidade, um lamentável fato que ocupa diariamente um considerável espaço na mídia brasileira diz respeito aos nossos jovens, que estão morrendo, vítimas da violência urbana, isso em uma proporção alarmante.

Outrossim, compreendemos que a dificuldade do acesso aos direitos constitucionalmente assegurados, apesar de todos nós sermos considerados como sujeitos de direitos, é uma situação recorrentemente vivenciada entre as pessoas que habitam os ambientes considerados degradados, haja vista não possuírem infra-estrutura adequada; serviços públicos, como atendimento médico eficaz, por exemplo; transporte público; segurança; entre outros - de boa qualidade, o que levam as pessoas a buscarem ansiosamente a saída desses locais, não estabelecendo, desse modo, laços sociais com a comunidade. De maneira que, na precariedade destes vínculos - considerados instrumentos importantes do controle social informal, principalmente pelos nossos jovens que são diretamente atingidos, pois ficam alheios às referências de sociabilidades primárias, sujeitando-se, então, à busca de sentido para a vida em outros focos: crime, drogas, entre outras atrocidades. Assim sendo, o mundo obscuro da violência torna-se bastante visível para essa juventude vulnerável, que passa a levá-lo de forma banal.

Foi igualmente concluído, que uma das principais contribuições da Escola de Chicago para a Criminologia foi a de negar a relação entre o crime e os fatores puramente 
psicogenéticos, substituindo tal ideia pela teoria de que os impactos dos processos históricos vivenciados por cada sociedade podem influenciar diretamente diversos setores da cidade, e, consequentemente, resultar em desfechos nas áreas sociais, econômicas, culturais etc.

Por fim, acreditamos que quanto à questão da violência urbana, a prevenção ainda seja a melhor saída, estando isso em conformidade com a perspectiva abordada pelos estudos da Ecologia Humana. De fato, na medida em que o capital social é fortalecido dentro das comunidades, juntamente com os cuidados especiais que as áreas deterioradas necessitam, por intermédio de programas sociais que levem em consideração a participação efetiva dos residentes, enfim, a partir de tudo isso existirá uma forte probabilidade para que os índices de criminalidade diminuam. Com relação àquelas pessoas que já se encontram inseridas no quadro da criminalidade, em especial os jovens, também se faz mister o seu tratamento adequado. Portanto, a modificação dos paradigmas até então utilizados na nossa estrutura social, como também no âmbito do nosso ordenamento jurídico, especialmente no que concerne à faixa etária jovem, será de extrema relevância para a eficácia do ideal de ressocialização.

\section{REFERÊNCIAS}

ABRAMOVAY, M. et al. Gangues, galeras, chegados e rappers: juventude, violência e cidadania nas cidades da periferia de Brasília. Rio de Janeiro: Garamond, 2004.

Juventude, violência e vulnerabilidade social na América Latina: desafios para políticas públicas. Brasília : UNESCO, BID, 2002.

; PINHEIRO, L. C. Violência e Vulnerabilidade Social. In: FRAERMAN, Alicia Inclusión Social y Desarrollo: Presente y futurode La Comunidad IberoAmericana. Madri: Comunica. 2003.

AMADO, J. Capitães da Areia. São Paulo: Companhia das letras, 2008.

ANDRADE, C. C. de. Entre gangues e galeras: juventude, violência e sociabilidade na periferia do Distrito Federal. Brasília, 2007. Tese de Doutorado em Antropologia Social, UNB.

ARENDT, H. A Condição Humana. 11. ed. Rio de Janeiro: Forense, 2010.

As Origens do Totalitarismo: antissemitismo, imperialismo, totalitarismo. São Paulo: Companhia das Letras, 2013. 
Revista da Faculdade de Direito-RFD-UERJ- Rio de Janeiro, n. 28, dez. 2015

BECKER, H. S. Outsiders: estudos de sociologia do desvio. Rio de Janeiro: Zahar, 2008.

BRASIL. Constituição (1988). Constituição da República Federativa do Brasil. Brasília, DF: Senado Federal: Centro Gráfico, 1988.

CAPEZ, F. Curso de Direito Penal - parte geral. 12. ed. São Paulo: Saraiva, 2008. v.1.

CARA, D; GAUTO, M.Juventude: percepções e exposição à violência In: Juventudes: outros olhares sobre a diversidade. Brasília : Ministério da Educação, Secretaria de Educação Continuada, Alfabetização e Diversidade. Unesco, 2007.

COULON, A. Escola de Chicago. São Paulo: Papirus, 1995.

FERREIRA, Aurélio B. de H. Mini Aurélio. 5. ed. Botafogo - RJ: Nova Fronteira, 2001.

FREITAS, W. C. de P. Espaço urbano e criminalidade: lições da Escola de Chicago. São Paulo: IBCCRIM, 2002.

HARVEY, D. O Direito à Cidade. Revista Lutas Sociais, n. 29, p. 73-89, jul./dez., São Paulo, 2012.

LUTTERS, W. G; ACKERMAN, M. S. An introduction to the Chicago School of Sociology.Interval Research Proprietary, 1996. Disponível em: 〈http://userpages.umbc.edu/ lutters/pubs/1996_SWLNote961_Lutters,Ackerman.pdf> Acesso em: 09.02.2014.

MERTON, R. K. Sociologia: Teoria e estrutura. Tradução de Miguel Maillet. São Paulo. MestreJou, 1968 ;

MISKOLSCI, R. Do desvio às diferença. Revista Teoria \& Pesquisa, n. 47, [s.1.], jul/dez, 2005.

MISSE, M. Malandros, marginais e vagabundos: a acumulação social da violência no Rio de Janeiro. 1999. Tese (Doutorado em Sociologia) - Iuperj, Rio de Janeiro, 1999.

NASCIMENTO, E. Dos excluídos necessários aos excluídos desnecessários. In: . et al. No meio da rua: nômades, excluídos e viradores. Rio de Janeiro: Garamond, 2003.

PARK, R. On Social Control and Collective Behavior. Chicago: The University of Chicago Press, 1967.

.The City: suggestions for investigation of human behavior in the urban environment. London: The University of Chicago Press, 1967.

PUTNAM, R. D. Comunidade e democracia: a experiência da Itália moderna. São Paulo: FGV, 2000. 
SHECAIRA, S. S. Criminologia. 5.ed. São Paulo: Revista dos Tribunais, 2013.

SORRENTINO, A. The Chicago Area Project after 25 years. In:Federal Probation. Washington, DC: Administrative Office of the U.S. Courts, v. 23, June, 1959.

SCHLOSSMAN, S. SHAVELSON, R. ZELLMAN, G. Delinquency prevention in south Chicago: a fifty-year assessment of the Chicago Area Project. Santa Monica, C.A; Rand, May, 1984.

TANGERINO, D. de P. C. Crime e cidade: violência urbana e a Escola de Chicago. Rio de Janeiro: Lumen Juris, 2007.

WALSELFISZ, J. J. Mapa da Violência 2013 - Homicídios e Juventude no Brasil. Brasília: Secretaria-Geral da Presidência da República, 2013.

Mapa da Violência 2014 - Os Jovens do Brasil. Brasília: SecretariaGeral da Presidência da República, 2014. 